\title{
The behavioural effects of undernutrition in confined farm animals
}

\author{
BY ALISTAIR B. LAWRENCE, E. M. CLAUDIA TERLOUW \\ AND ILIAS KYRIAZAKIS \\ Genetics and Behavioural Sciences Department, The Scottish Agricultural College Edinburgh, \\ West Mains Road, Edinburgh EH26 OQE
}

The post-war intensification of agriculture in the UK and other industrial societies has brought with it an increase in concern over the welfare of farm animals. The Farm Animal Welfare Council, which has the responsibility of overseeing the development of humane methods of animal production, has promoted five basic 'freedoms' to protect farm animals from suffering, and these are now specified in the introduction to all Codes of Recommendations for the Welfare of Livestock (e.g. Ministry of Agriculture, Fisheries and Food, 1991). The first of these freedoms is that animals kept for farming purposes should be free from hunger and malnutrition. In the present review we will consider examples where this freedom is not being fulfilled and the implications of this for welfare of the animals concerned.

\section{FEEDING MOTIVATION}

In order to understand how undernutrition might affect the behaviour of farmed animals it is necessary to briefly review the controls of feeding behaviour.

A traditional view of feeding behaviour is that the brain senses when a physiological variable, such as glucose, deviates from a 'set-point' resulting in appetitive and consummatory feeding behaviour (for a review, see Toates, 1986). Appetitive behaviour involves the searching for, location and manipulation of food after which actual consummatory activity (feeding) can take place. Feeding is seen as being under negative feedback control, responding only to an animal's internal state, and acting to return the internal state to the defined set-point.

There is no doubting the important influence of internal nutritional state on feeding behaviour. For example, food intake increases, up to a point, in response to dietary dilution (Mraz et al. 1958). Animals can also accurately reduce their food intake to compensate for nutrients injected directly into their stomachs (Pekas, 1983). However, the set-point theory has suffered because there is little agreement over which factor(s) is being monitored to control feeding, and because the relationship between physiological changes and behaviour is far from being as simple as the model suggests (for a review of the 'glucostatic' model, see Grossman, 1986). Perhaps the greatest limitation of the simple set-point approach is its emphasis on the role of the internal state. There is substantial evidence to illustrate the importance of environmental (sensory) cues in eliciting feeding; even in simple invertebrates the internal state is not sufficient to maintain feeding motivation and it is also necessary to present an external stimulus to elicit feeding behaviour (Kandel, 1979).

The importance of both internal and external factors have been acknowledged in the development of current motivational models (Toates, 1986). Motivations are viewed as temporary and reversible brain states induced by internal and external signals and 
resulting in the tendency to perform specific behaviours. In the 'state-space' approach of McFarland and his co-workers (e.g. McFarland \& Houston, 1981), motivational state is represented as a point in a multi-dimensional space, bounded by axes representing the internal and external causal factors that elicit the state. In set-point models the internal state (hunger in the case of feeding), is often seen as a unitary variable. However, it is clear that hunger is multi-dimensional in so far as feeding behaviour may be affected by the specific content of food (see p. 221). The state-space approach can readily represent the combination of different internal factors that contribute to the hunger state. An external factor (e.g. a food item) that stimulates motivational changes is often referred to as an 'incentive' and is itself the product of various characteristics, for example the availability and sensory qualities of the food. Motivational tendency results from the multiplicative combination of hunger and incentive (Baerends et al. 1955). For example, the tendency to seek for food that arises from a low hunger in the presence of a food with a high incentive, can be the same as that from a high hunger with a low-incentive food.

As animals can only perform one behaviour at a time it is clear that there must be a decision-making process that determines which behaviour assumes priority. The statespace approach assumes that the behaviour being expressed at a given moment has the greatest priority. Thus, feeding motivation must compete with other candidate behaviours for overt behavioural expression, and the length of time devoted to feeding does not simply reflect feeding tendency but also the strength of competing tendencies such as drinking. Logically, the current behaviour (say feeding) will continue until either another motivational tendency rises and inhibits feeding (competition), or until the feeding tendency decreases and allows (or disinhibits) expression of the next strongest tendency (McFarland, 1969). However, simulations of decision-making processes for behavioural transitions based on this simple approach have resulted in the animal oscillating or dithering between activities (Houston \& Sumida, 1985). Such dithering may be prevented in nature by the action of positive feedback (McFarland, 1971), where the tendency to perform a behaviour is boosted by its performance. There is some experimental evidence for positive feedback resulting from feeding behaviour (Wiepkema, 1971).

In addition to these processes relating to specific motivations it is clear that a number of non-specific processes such as learning can modulate expression of motivational states (e.g. Bindra, 1976). Learning can be distinguished from motivation as giving rise to relatively non-reversible changes in behaviour. For example, the repeated presentation of a food-related stimulus progressively enhances reflex oral activity, a process known as sensitization (Kandel, 1979). In classical conditioning a previously neutral stimulus, such as a sound, becomes associated with a motivationally significant stimulus (reinforcer) such as food. In operant conditioning an association is formed between a behavioural response (e.g. pressing a lever) and a reinforcer such as food (for a review of conditioning, see Mackintosh, 1983). In these examples the adaptive function of learning is to shape behaviour to increase its effectiveness in achieving motivational goals. The importance of learning in feeding behaviour has been demonstrated in a number of ways. For example, a large literature has confirmed that the sensory qualities of a food become associated with its post-ingestive effects, thereby influencing future feeding choices (e.g. Booth, 1972). In other words the incentive value that an animal attaches to the sensory aspects of food alters in response to the animal's internal state (e.g. Cabanac \& Ferber, 1987). 
Arousal is another relevant non-specific modulator of motivational expression. When animals are exposed to relatively mild levels of peripheral stimulation or when motivated behaviour is physically prevented ('thwarted'), they often show responses that are not explicable entirely in terms of specific motivations. For example, when a handled rat is returned to its home cage it will often begin a feeding bout (Roper, 1980). Thirsty rats prevented from drinking engage in a number of other activities including eating, grooming and exploration (Roper, 1984). The behaviours performed under such circumstances are often described as frantic or even bizarre and they are certainly performed at a faster than normal rate (Roper, 1984). These responses measured under experimental conditions have relevance to farm animals where confinement may often thwart behaviour. They may be explained on the grounds that the stimulation (e.g. thwarting) induces an increased state of general behavioural activation or arousal that facilitates and enhances performance of non-thwarted behaviours. Behavioural arousal will be used here to describe non-specific excitatory links between behaviours whilst accepting that arousal may not in fact constitute a unified process (e.g. Kandel, 1979).

\section{Summary}

Current theory sees the motivational tendency underlying feeding resulting from the combination of the internal hunger state and external stimuli; the internal and external factors are themselves the product of a set of contributing factors. The resulting feeding tendency has to compete with other tendencies to be expressed; the cessation of a feeding bout may not necessarily reflect a significant reduction in feeding tendency but its inhibition by another stronger tendency. Positive feedback, from feeding behaviour, elevates feeding tendency preventing it from being too quickly re-inhibited; negative feedback from the consequences of behaviour ultimately reduces feeding tendency. Non-specific processes are also important in modulating the behavioural expression of motivational states. Learning has a number of important roles in feeding, such as allowing the sensory qualities of food to act as pre-absorptive cues to the nutrient content of foods. Increased arousal can be induced by general stimulation or thwarting of behaviour and results in a general excitation of behaviour.

Using this as a theoretical base, we will consider various ways in which farm animals may be exposed to undernutrition and the behavioural consequences of that undernutrition.

\section{SOURCES OF UNDERNUTRITION IN CONFINED FARM ANIMALS}

There are a number of circumstances where confined farm animals are exposed to undernutrition and potentially an enhanced feeding tendency.

\section{Specific-nutrient deficits where food is available ad lib.}

Where food is offered ad lib. it may still be common for individuals to experience specific nutrient deprivation or malnutrition. Motivational theory suggests that the feeding system should be responsive to the nutrient content of foods (see p. 220), and a number of farmed species are able to select a diet appropriate to their nutritional requirements when given a free selection from a range of foods. Domesticated fowl (Rose \& Michie, 
1982), sheep (Cropper, 1987) and pigs (Kyriazakis et al. 1990) have all shown the ability to select a diet to meet their apparent nutritional requirements. In the case of pigs it has been demonstrated that the selected protein content of the diet decreases with age (Kyriazakis et al. 1990), is higher in entire males than females, and increases following a period of protein restriction (Kyriazakis \& Emmans, 1991). These results support the view that pigs can select a diet with a varying protein content that reflects their genotype, stage of growth and previous feeding history. There is evidence that both learning and preprogrammed responses may be involved in diet selection. Rozin \& Kalat (1971) have suggested that selection of an appropriate diet is based more on general sensations of sickness and health than on detection of specific deficiencies. Under free-ranging (unconfined) conditions, where there is no specific appetite for the nutrient, the inexperienced animal may show a rather general increase in sampling of foods, until trial and error or learning from social models (Lynch et al. 1983), indicates foods yielding the deficient nutrient. There is also evidence that animals may have unlearned appetites for specific nutrients. For example, protein-depleted rats have been shown to select a significantly higher proportion of proteins that they had not previously encountered than protein-replete rats, with the preference for protein in the protein-depleted animals being expressed as early as the first minute of the test (Deutsch et al. 1989).

Under commercial farming conditions it is common to provide animals with a single diet, normally based on the nutritional requirement of the average individual between certain weights. It is inevitable that for all individuals, either as a result of their genotype, their current stage of growth and/or their previous experience, there will be at some point a discrepancy between the nutritional content of the single diet, and their actual requirements for specific nutrient(s). This discrepancy will be monitored by the feeding motivational system, increasing feeding tendency and the expression of foraging behaviour. In the first instance, the foraging behaviour will be directed towards the available food, being of higher incentive value for feeding than other available stimuli. For example, pigs offered a single diet deficient in protein, increased their intake of the food in a compensatory response for the protein deficiency (Kyriazakis et al. 1990). There may, however, be circumstances where the magnitude of the specific-nutrient deficit is large and the animal is unable to compensate fully by increasing intake either because of physical or environmental limitations on further intake or deleterious effects of the increased amounts of non-limiting nutrients. Under these circumstances there will be insufficient negative feedback from the consequences of ingestion to reduce feeding tendency.

\section{General nutrient restriction where food is available ad lib.}

In addition to specific-nutrient deficiency farm animals can experience a general nutrient restriction when food is available ad lib. For example, ruminants grazing in hill or upland areas, despite spending most of their active time foraging, are probably unable to meet their preferred nutrient intake and may even move into negative energy loss. Restrictions placed on animals' feeding behaviour by other group members are also common. Farm animals are social species and can show social synchrony and facilitation of behaviour, with group members generally showing a preference to feed at the same time (Young \& Lawrence, 1993). Where the food source limits access to one or a few individuals, this can result in certain animals being prevented from feeding freely by 
other group members. In some instances farm animals can respond to social restriction on their feeding activity by changing when or how they feed, for example by increasing their feeding rate (Young \& Lawrence, 1993). In other instances they may be unable to compensate and suffer a nutrient restriction. For example, in hill sheep feeding from supplementary foodblocks younger ewes have been shown to consume less from the foodblock relative to older ewes as a result of social competition (Lawrence \& Wood-Gush. 1988).

\section{Undernutrition as a result of imposed nutrient restriction}

There are a number of cases where farm animals are deliberately exposed to a general nutrient (food) restriction, the most widespread examples being the restricted feeding regimens imposed on the breeding populations of pigs and the parent stock for the broiler industry (broiler breeders). Sows are commonly placed on a restricted feeding regimen during pregnancy to prevent excessive body fat and associated problems including reduced conception rates and lameness, and to reduce food costs (Whittemore et al. 1988). The level of restriction for sows varies with parity (nulliparous sows (gilts) being less restricted) but broadly amounts to $1 \cdot 3$ times maintenance or $60 \%$ of the ad lib. intake of a concentrated food (e.g. Agricultural and Food Research Council, 1990). Boars are similarly food restricted. Both sexes of broiler breeder are food restricted to prevent reductions in fertility and other problems such as heat stress and lameness which occur if they are given ad lib. access to food (Hocking et al. 1989). Savory et al. (1993) has shown that broiler breeders given ad lib. access to a concentrate food will consume two or four times as much as birds on commercial levels of food restriction, depending on whether birds of the same age or weight are compared. Using the proportion of ad lib. intake as a common index this suggests that broiler breeders in practice are exposed to levels of food restriction at least twice as great as those applied to pigs.

It is only recently that the behavioural consequences of restricted feeding regimens have been considered. One technique for measuring the effect of food restriction on feeding motivation is to condition animals to perform an operant response such as pressing a panel to receive small food rewards. The level of operant responding (or 'work') can be taken as an index of feeding tendency (Teitelbaum, 1966). In a series of experiments, the commercial level of food restriction for sows and boars has been demonstrated to give rise to high work rates across the day even in the immediate post-feeding period (Lawrence et al. 1988; Lawrence \& Illius, 1989). Similar results have been obtained from broiler breeders (Savory et al. 1993). These results suggest that food restriction in pigs and broiler breeders results in a substantially heightened feeding tendency, and that this feeding tendency is as great following the meal as at other times presumably reflecting the effects of positive feedback from feeding behaviour (Wiepkema, 1971), and a lack of negative feedback from the consequences of ingestion. They also indicate that the feeding motivational system does not adapt to the imposed restriction, a view supported by the observation that feeding rate in food-restricted gilts, increases over pregnancy, whilst gilts on a higher nutritional plane show no such increase (Terlouw et al. 1991a). Levels of feeding tendency in food-restricted pigs and broiler breeders (at least during and immediately after feeding) may in part reflect, therefore, an accumulating (chronic) hunger, perhaps based on the difference between actual and potential (genetic) growth rates (Marwine \& Collier, 1971). 


\section{Summary}

Specific and general nutrient deficits of varying severity can arise in farm animals for a number of reasons. In practice deficits resulting from the individual being unable to match its nutritional requirements to the nutrient content of the ad lib. (single) food on offer may be relatively mild. More severe deficits are likely to be induced by imposing actual restrictions on food intake. There is some evidence that the level of deficit is broadly reflected by increases in feeding tendency, with commercial levels of food restriction giving rise to substantially elevated feeding tendency.

We will now consider how expression of the feeding tendency that arises from nutrient deficit is affected by the confined environments in which farm animals are often housed.

\section{EXPRESSION OF FORAGING BEHAVIOUR IN CONFINED FARM ANIMALS}

The feeding motivation system has the general function of ensuring sufficient nutrient intake to ensure survival and growth. Under free-ranging conditions the increased feeding tendency arising from nutrient deficit will ordinarily direct behaviour towards the finding and consuming of food items to satisfy the deficit until such time as feeding is reduced below the level of other competing tendencies. For example, sows in the Edinburgh Pig Park (a 5 ha area of pasture and open woodland) offered a restricted level of nutrients spent more than $50 \%$ of their active time in activities associated with foraging (Stolba \& Wood-Gush, 1984). Where confined farm animals are exposed to nutrient deficit (see p. 223) a motivational approach allows for two alternatives. First, feeding tendency is reduced. In the case of a specific-nutrient deficit this could be in response to the reduced incentive value of the nutrient deficient food. In food-restricted animals, it could result from food no longer being present at the end of the meal. There is evidence, reviewed previously, that hunger alone is not sufficient to maintain feeding activity. Second, the animal will direct its foraging activity towards the most appropriate available stimuli, i.e. those stimuli that result in greatest sensory feedback (incentive) and the maintenance of the feeding tendency. Current empirical evidence supports the second of these alternatives, and to illustrate this we will take examples from studies of growing pigs and food-restricted sows and broiler breeders.

\section{Growing pigs}

Growing pigs, although offered $a d$ lib. access to food may still in practice experience specific nutrient deficits (see p. 221). Growing pigs offered a diet deficient in tryptophan increase their explorative behaviour (interpreted as foraging behaviour) in an 'openfield' test, relative to pigs offered a diet adequate in tryptophan (Meunier-Salaun et al. 1991). Similarly, in individually housed growing pigs an ad lib. diet deficient in protein was found to increase general activity, walking and rooting of straw, relative to pigs fed on a diet excessive in protein or pigs offered a choice between the two diets, although the dietary effect on behaviour reduced over time (Jensen et al. 1993). An interpretation of these results is that the protein-deficient pigs were unable, perhaps because of environmental limitations, to ingest sufficient of the diet to reduce hunger (and specifically their appetite for protein). They then directed foraging behaviour to other alternative stimuli and straw provided the greatest sensory feedback (or incentive), sufficient to sustain the feeding tendency and the behaviour. The reduction in the effect over time may indicate a 
lowering in the incentive value of the straw, perhaps in response to its failing to correct the protein deficiency.

Growing pigs are almost always housed in social groups where sporadic episodes of behaviours such as tail and ear biting can occur (Van Putten, 1969). There are considerable welfare and economic implications attached to such outbreaks, reflecting the obvious pain experienced by the recipient and the potential for infection and condemnation of the carcass (Penny \& Hill, 1974). The causation of tail biting is poorly understood, although it has often been attributed to general effects of confined environments such as boredom (Sambraus, 1985). Alternatively, Van Putten (1969) has argued that tail biting is the end-result of the tendency for growing pigs to root and chew objects in their environment, and an extension of this argument would suggest that foraging activity resulting from a specific-nutrient deficiency could be directed at the bodies of pen-mates. A similar argument has been developed to explain the causation of feather-pecking in hens (Blockhuis, 1989). Folic acid supplementation was found to decrease activity in ad lib.-fed growing pigs and reduce nibbling of pen-mates in growing pigs restricted to $95 \%$ of their ad lib. intake (Robert et al. 1991). The blood from any resulting wound could act as an incentive to sustain the behaviour. Pigs show an enhanced preference for chewing on blood-impregnated model tails as opposed to plain models when dietary salt is eliminated (Fraser, 1987a) or when dietary protein reduced (Fraser et al. 1991). Also when pigs were offered a diet supplemented with synthetic amino acids those that gained weight more rapidly had a reduced preference for blood relative to individuals with reduced weight gain (Fraser et al. 1991). While blood clearly represents an incentive for foraging resulting from salt deficiency, it does not efficiently reverse a protein shortage, suggesting that protein deficiency results in a general increase in attraction to a variety of oral stimuli (Fraser et al. 1991). The unpredictable nature of tail biting may reflect the interaction between the rather random manner in which individuals find themselves nutrient deprived on single ad lib. diets (see p. 222), and individual differences in oral (chewing) behaviour and attraction for blood (cf. Fraser, $1987 b$ ).

\section{Food-restricted sows and broiler breeders}

Food-restricted sows and broiler breeders are generally placed in environments that restrict the expression of behaviour; for example, sows are still commonly kept in individual crates or tether stalls.

It is common under such physically restrictive conditions to observe the development of abnormal stereotypic activities. Stereotypies are behaviours that are regularly repeated in a very similar way and lacking an obvious function (Ödberg, 1978). Closely confined sows express a range of stereotypic activities such as bar-biting, chainmanipulation and excessive drinking (e.g. Fraser, 1975; Cronin, 1985; Terlouw et al. 1991a); broiler breeders peck stereotypically at objects in the pen, including walls and feeders (Kostal et al. 1992). Stereotypies are often regarded as arising from situations of chronic frustration or stress and representing indicators of poor welfare (Wiepkema et al. 1987). The development of stereotypies is often attributed to a lack of stimulation and resulting boredom (Wemelsfelder, 1990); however, there is increasing evidence that food restriction is an important causal factor in development of stereotypies in farm animals. For example, in sows (Rushen, 1984; Terlouw et al. 1991 b) and broiler breeders (Kostal 
et al. 1992) the diurnal pattern of stereotypies is closely linked to feeding, with sterotypies largely being performed during the post-feeding period. Manipulations of food level have shown that oral stereotypies only develop in food-restricted gilts (Appleby \& Lawrence, 1987; Terlouw et al. 1991a) and broiler breeders (Savory et al. 1993). Stereotypies in sows have been shown not to be elicited by an arousing stimulus unrelated to feeding (a loud and novel sound), but in contrast to be specifically elicited by ingestion of even a small amount of food (Terlouw et al. 1993).

One interpretation of these results is that stereotypies, such as chain-manipulation and drinking in sows, are the behavioural expression of heightened feeding tendency in the post-feeding period (see p. 223), modified by the physical constraints of the environment (see Rushen et al. 1993). In this sense stereotypic behaviour appears analogous to the straw and pen-mate-directed activities observed in ad lib.-fed pigs (see pp. 224-225). There are, however, important differences between these two types of behaviour. First, a major characteristic of stereotypies is their lack of variability, with a high probability that the same limited number of behavioural elements will be repeated in a similar sequence. An important contributor to this reduced behavioural variability is likely to be the physically restrictive environment (e.g. tether stall) that channels the expression of foraging, such that only a limited number of simple behavioural elements are performed (Lawrence \& Terlouw, 1993). The degree of stereotypy is then in part a function of the extent to which the environment reduces complexity of the behaviour. The heightened level of hunger reduces the requirement for sensory feedback from the environment to maintain the feeding tendency and prevent its inhibition. Second, stereotypies are also characterized by their persistence with animals often performing the behaviours for many hours of the day (Rushen, 1985). A number of different processes may be responsible for this characteristic, including lack of negative feedback from ingestion and little competition from other tendencies which would normally end the behaviour (cf. Hughes \& Duncan, 1988). The small meal may also increase behavioural arousal (Killeen et al. 1978), and as a result food-restricted animals could have an increased tendency to engage in active behaviours, facilitating performance of behaviours with a high motivational tendency (Terlouw et al. 1993). Finally, the repeated performance of a limited sub-set of behaviours (as a result of channelling and processes such as arousal causing short-term persistence of behaviour) could lead to sensitization of underlying neutral controls which would further facilitate persistence of the behaviour (Dantzer, 1986).

\section{Summary}

Results suggest that where the animal is unable to engage in functional feeding to reduce nutrient deficit, it may still continue to engage in feeding by directing its feeding behaviour to other alternative stimuli. If feeding is to be maintained where there are constraints on further intake, the alternative stimuli to food must be of sufficient incentive to prevent feeding being inhibited by other tendencies. Alternatives to food then are likely to be chosen on the basis of their sensory (incentive) qualities, and the precise form of feeding behaviour will depend on the interaction between the feeding tendency and the choice of available stimuli. Growing pigs offered single diets ad lib. and experiencing relatively mild deficits of specific-nutrients, may direct this behaviour towards pen-mates as alternative foraging stimuli, with blood resulting from this foraging 
activity acting as a further incentive to sustain the behaviour. If specific-nutrient deficits in growing pigs are generally mild then feeding may only be sustained in the presence of high incentives such as pen-mates. However, it is not always clear why stimuli such as pen-mates continue to attract foraging activity when they provide little of the deficient nutrients underlying the behaviour. Where the nutrient deficit is more extreme, such as in food-restricted sows and broiler breeders even stimuli with low incentive (e.g. chains, bars or walls) may be sufficient to maintain feeding tendency. The environment, by only allowing simple and non-complex behaviour to be performed, channels the expression of feeding behaviour into simple and repetitive stereotypic behaviours. Other behavioural processes such as arousal and sensitization may facilitate the marked persistence of stereotypies.

\section{CONCLUSIONS}

We have reviewed a number of examples where farm animals are exposed to undernutrition and hunger in contravention of the 'Welfare Codes'. As a general theme we have highlighted the importance of the interaction between the animal's internal hunger state and the available environmental stimuli. Research indicates that specific nutritional deficits or general nutrient restriction will increase hunger (the internal state) and an increased probability that foraging responses will be elicited. Farm animals are, however, generally kept under conditions that restrict the expression of appropriate foraging behaviour, and the behaviour may then be performed with other stimuli, with the choice of stimuli depending on level of sensory feedback (or incentive value). Welfare problems arise where other members of the group are chosen as foraging stimuli leading to cannibalistic behaviour, or where the heightened feeding tendency and the restrictive environment combine in the development of unduly repetitive and persistent stereotypic behaviour. This analysis suggests that these problems can be resolved either by seeking to reduce the internal hunger state, or by allowing the animal to find more appropriate expressions of its foraging behaviour.

\section{REFERENCES}

Agricultural and Food Research Council (1990). Nutrient Requirements for Sows and Boars. Slough: Commonwealth Agricultural Bureaux.

Appleby, M. C. \& Lawrence, A. B. (1987). Food restriction as a cause of stereotypic behaviour in tethered gilts. Animal Production 45, 103-111.

Baerends, G. P., Brouwer, R. \& Waterbolk, H. Tj. (1955). Ethological studies on Lebistes reticulatus (Peters), I: An analysis of the male courtship pattern. Behaviour 8, 249-334.

Bindra, D. L. (1976). A Theory of Intelligent Behavior. New York: Wiley.

Blockhuis, H. J. (1989). The development and causation of feather pecking in the domestic fowl. PhD Thesis, The Agricultural University of Wageningen, The Netherlands.

Booth, D. A. (1972). Satiety and behavioural caloric compensation following intragastric glucose loads in the rat. Journal of Comparative Physiological Psychology 78, 412-432.

Cabanac, M. \& Ferber, C. (1987). Pleasure and preference in a two-dimensional sensory space. Appetite 8, $15-28$.

Cronin, G. M. (1985). The development and significance of abnormal stereotypes behaviour in tethered sows. PhD Thesis, Agricultural University of Wageningen, The Netherlands.

Cropper, M. R. (1987). Growth and development of sheep in relation to feeding strategy. PhD Thesis, University of Edinburgh.

Dantzer, R. (1986). Behavioural, physiological and functional aspects of stereotypes behaviour. A review and reinterpretation. Journal of Animal Science 62, 1776-1786. 
Deutsch, J. A., Moore, B. O. \& Heinrichs, S. C. (1989). Unlearned specific appetite for protein. Physiology and Behaviour 46, 619-624.

Fraser, D. (1975). The effect of straw on the behaviour of sows in tether stalls. Animal Production 21, 59-68.

Fraser, D. (1987a). Mineral-deficient diets and the pig's attraction to blood: implications for tail-biting. Canadian Journal of Animal Science 67, 909-918.

Fraser, D. (1987b). Attraction to blood as a factor in tail-biting by pigs. Applied Animal Behaviour Science 17, 61-68.

Fraser, D., Bernon, D. E. \& Ball, R. O. (1991). Enhanced attraction to blood by pigs with inadequate dietary protein supplementation. Canadian Journal of Animal Science 71, 611-619.

Grossman, S. P. (1986). The role of glucose, insulin and glucagon in the regulation of food intake and body weight. Neuroscience and Biobehavioural Reviews 10, 295-315.

Hocking, P. M., Waddington, D., Walker, M. A. \& Gilbert, A. B. (1989). Control of the development of the ovarian follicular hierarchy in broiler breeder pullets by food restriction during rearing. British Poultry Science 30, 161-174.

Houston, A. I. \& Sumida, B. (1985). A positive feedback model for switching between two activities. Animal Behaviour 33, 315-325.

Hughes, B. O. \& Duncan, I. J. H. (1988). The notion of ethological 'need', models of motivation, and animal welfare. Animal Behaviour 36, 1696-1707.

Jensen, M. B., Kyriazakis, I. \& Lawrence, A. B. (1993). The activity and straw directed behaviour of pigs offered foods with different crude protein content. Applied Animal Behaviour Science (In the Press).

Kandel, E. R. (1979). Behavioral Biology of Aplysia. San Francisco: Freeman.

Killeen, P. R., Hanson, S. J. \& Osborne, S. R. (1978). Arousal: its genesis and manifestation as response rate. Psychological Reviews 85, 571-581.

Kostal, L., Savory, C. J. \& Hughes, B. O. (1992). Diurnal and individual variation in behaviour of restricted-fed broiler breeders. Applied Animal Behaviour Science 32, 361-374.

Kyriazakis, I. \& Emmans, G. C. (1991). Diet selection in pigs: dietary choices by growing pigs following a period of underfeeding with protein. Animal Production 52, 337-346.

Kyriazakis, I., Emmans, G. C. \& Whittemore, C. T. (1990). Diet selection in pigs: choices made by growing pigs given foods of different protein concentrations. Animal Production 51, 189-199.

Lawrence, A. B., Appleby, M. C. \& Macleod, H. A. (1988). Measuring hunger in the pig using operant conditioning: The effect of food restriction. Animal Production 47, 131-137.

Lawrence, A. B. \& Illius, A. W. (1989). Methodology for measuring hunger and food needs using operant conditioning in the pig. Applied Animal Behavior Science 24, 273-285.

Lawrence, A. B. \& Terlouw, E. M. C. (1993). A review of behavioural factors involved in the development and continued performance of stereotypic behaviours in pigs. Journal of Animal Science (In the Press).

Lawrence, A. B. \& Wood-Gush, D. G. M. (1988). Influence of social behaviour on utilization of supplemental feedblocks by Scottish hill sheep. Animal Production 46, 203-212.

Lynch, J. J., Keogh, R. G., Elwin, R. L., Green, G. C. \& Mottershead, B. E. (1983). Effects of early experience on the post-weaning acceptance of whole grain wheat by fine-woolled Merino lambs. Animal Production 36, 175-183.

McFarland, D. J. (1969). Mechanisms of behavioural disinhibition. Animal Behaviour 17, $238-242$.

McFarland, D. J. (1971). Feedback Mechanisms in Animal Behaviour. London: Academic Press.

McFarland, D. J. \& Houston, A. I. (1981). Quantitative Ethology: The State Space Approach. London: Pitman Press.

Mackintosh, N. J. (1983). Conditioning and Associative Learning . Oxford: Clarendon Press.

Marwine, A. G. \& Collier, G. (1971). Instrumental and consummatory behaviour as a function of weight loss and weight maintenance schedule. Journal of Comparative and Physiological Psychology 74, 441-447.

Meunier-Salaun, M. C., Monnier, M., Coileaux, Y., Seve, B. \& Henry, Y. (1991). Impact of dietary tryptophan and behavioural type on behaviour, plasma cortisol, and brain metabolites of young pigs. Journal of Animal Science 69, 3689-3698.

Ministry of Agriculture, Fisheries and Food (1991). Codes of Recommendations for the Welfare of Livestock: Pigs. London: MAFF.

Mraz, F. R., Boucher, R. V. \& McCartney, M. G. (1958). The influence of dietary energy and protein on growth responses in chickens. Poultry Science 37, 1308-1313.

Ödberg, F. (1978). Abnormal behaviours: Stereotypies. Introduction to the Round Table. In Proceedings of the 1st World Congress on Ethology and Applied Zootechnics, pp. 475-480 [G. Garsi, editor]. Madrid: Industrias Grafices Espana. 
Pekas, J. C. (1983). A method for direct gastric feeding and the effect on voluntary ingestion in young swine. Appetite 4, 22-30.

Penny, R. H. C. \& Hill, F. W. G. (1974). Observations on some conditions in pigs at the abattoir with particular reference to tail-biting. Veterinary Record 94, 174-180.

Robert, S., Matte, J. J. \& Girard, C. L. (1991). Effect of feeding regimen on behaviour of growing-finishing pigs supplemented or not supplemented with folic acid. Journal of Animal Science 69, 4428-4436.

Roper, T. J. (1980). 'Induced' behaviour as evidence of non-specific motivational effects. In Analysis of Motivational Effects, pp. 221-242 [F. M. Toates and T. R. Halliday, editors]. London: Academic Press.

Roper, T. J. (1984). Response of thirsty rats to absence of water: frustration, disinhibition or competition? Animal Behaviour 32, 1225-1235.

Rose, S. P. \& Michie, W. (1982). The food intakes and growth of choice-fed turkeys offered balancer mixtures of different compositions. British Poultry Science 23, 547-554.

Rozin, P. \& Kalat, J. (1971), Specific hungers and poison avoidance as adaptive specializations of learning. Psychological Reviews 78, 459-486.

Rushen, J. (1984). Stereotypic behaviour, adjunctive drinking and the feeding periods of tethered sows. Animal Behaviour 32, 1059-1067.

Rushen, J. (1985). Stereotypies, aggression and the feeding schedules of tethered sows. Applied Animal Behaviour Science 14, 137-147.

Rushen, J., Lawrence, A. B. \& Terlouw, E. M. C. (1993). The motivational basis of stereotypies. In Stereotypic Animal Behaviour: Fundamentals and Applications to Animal Welfare [A. B. Lawrence and J. Rushen, editors]. Wallingford: Commonwealth Agricultural Bureaux (In the Press).

Sambraus, H. H. (1985). Mouth-based anomalous syndromes. In Ethology of Farm Animals, pp. $391-422$ [A. F. Fraser, editor]. Amsterdam: Elsevier.

Savory, C. J., Maros, K. \& Rutter, S. M. (1993). Assessment of hunger in growing broiler breeders in relation to a commercial restrictive feeding programme. Animal Welfare (In the Press).

Stolba, A. \& Wood-Gush, D. G. M. (1984). The identification of behavioural key features and their incorporation into a housing design for pigs. Annals Recherches de Veterinaire 15, 287-299.

Teitelbaum, P. (1966). The use of operant methods in the assessment and control of motivational states. In Operant Behavior. Areas of Research and Applications, pp. 565-608 [W. K. Honig, editor]. New York: Appleton-Century-Crofts.

Terlouw, E. M. C., Wiersma, A., Lawrence, A. B. \& Macleod, H. A. (1993). The effect of ingestion of food on performance of stereotypies in sows. Animal Behaviour (In the Press).

Terlouw, E. M. C., Lawrence, A. B. \& Illius, A. W. (1991a). Influences of feeding level and physical restriction on development of stereotypies in sows. Animal Behaviour 42, 981-991.

Terlouw, E. M. C., Lawrence, A. B., Ladewig, J., De Passille, A. M., Rushen, J. \& Schouten, W. (1991b). Relationship between plasma cortisol and stereotypic activities in pigs. Behavioural Processes 25, 133-153.

Toates, F. (1986). Motivational Systems. Cambridge: Cambridge University Press.

Van Putten, G. (1969), Objective observations on the behaviour of fattening pigs. Animal Regulation Studies 3, 105-118.

Wemelsfelder, F. (1990). Boredom and laboratory animal welfare. In The Experimental Animal in Biomedical Research, vol. 1, pp. 243-272 [B. E. Rollin and M. L. Kesel, editors]. Boca Raton, USA: CRC Press.

Whittemore, C. T., Smith, W. C. \& Philips, P. (1988). Fatness, live weight and performance responses of sows to food level in pregnancy. Animal Production 47, 123-130.

Wiepkema, P. R. (1971). Positive feedbacks at work during feeding. Behaviour 39, $2-4$.

Wiepkema, P. R., Van Hellemond, K. K., Roessingh, P. \& Romberg, H. (1987). Behaviour and abomasal damage in individual veal calves. Applied Animal Behaviour Science 18, 257-268.

Young, R. J. \& Lawrence, A. B. (1993). Feeding behaviour of pigs in groups monitored by a computerized feeding system. Animal Production (In the Press). 